\title{
REPRESENTAÇÕES DO COTIDIANO EM DOCUMENTÁRIOS DE PERIFERIA
}

\author{
Everyday life representions in documentaries of periphery
}

Representaciones de lo cotidiano en documentales de periferia

\author{
Gustavo Souza \\ Professor na Universidade Paulista (Unip) \\ gustavo03@uol.com.br
}

\begin{abstract}
Resumo
Pretendemos debater se a escolha do cotidiano como tema, por parte dos realizadores de cinema e audiovisual de diversas periferias brasileiras, reverte-se em um desdobramento político-discursivo. Para isso, as análises dos documentários escolhidos obedecem à seguinte orientação: como se apreende uma determinada vivência? Como resposta é possível inicialmente apontar: 1) a apropriação da experiência cotidiana e periférica para se reportar diretamente aos meios de comunicação de massa que constroem imagens e imaginários engessados sobre as periferias; 2) o abandono desse tom de resposta explícita para se ocupar do cotidiano periférico por meio de histórias do lugar, pessoas e sociabilidades.
\end{abstract}

Palavras-chave: Documentário. Cotidiano. Periferia.

\begin{abstract}
We intend to discuss the choice of the everyday life theme, by the film and audiovisual several Brazilian peripheries, reverses into a deployment political discoursive. For this, analyzes of selected documentaries adhere to the following guidance: how to seize a particular experience? In response it is possible to initially point: 1) the appropriation of everyday experience and peripheral to report directly to the means of mass communication that build and imaginary images plastered on the outskirts; 2) the abandonment of this explicit answer tone to engage the everyday peripheral through stories of the place, people and sociability
\end{abstract}

Keywords: Documentary. Everyday life. Periphery.

\section{Resumen}

Tenemos la intención de discutir si la elección del cotidiano como tema, por los realizadores del cine y audiovisual de varias periferias brasileñas, se convierte en una postura discursivopolítica. Para ello, el análisis de los documentales seleccionados se orientan a partir de un punto: cómo se percibe una experiencia de vida particular? En respuesta, es posible inicialmente indicar: 1) la apropiación de la experiencia cotidiana y periférica para se referir directamente a los medios de comunicación de masa que construyen imágenes e imaginarios 
PROGRAMA DE PÓS-GRADUAÇÃO EM COMUNICAÇÃO DA UNIVERSIDADE FEDERAL DE SANTA MARIA

fijos sobre las periferias, 2) el abandono de este tono de respuesta explícita para tratar el cotidiano periférico a través de historias del lugar, de la gente y sociabilidades.

Palabras clave: Documental. Cotidiano. Periferia.

\section{INTRODUÇÃO}

Os documentários realizados em diversas periferias brasileiras apresentam uma nítida diversidade em relação aos temas que abordam. Diante desse aspecto, este trabalho estabelece um recorte que se volta para a apreensão do cotidiano em suas diversas possibilidades imagético-sonoras. A hipótese que se quer testar é se a escolha de diversas nuances que compõem o cotidiano se reverte em um desdobramento discursivo-político nos filmes. Em outros termos, se a esfera da vida cotidiana torna-se um espaço de legitimação de discursos que tomam os filmes como suporte para a materialidade de um ponto de vista político.

Para tanto, analisarei alguns documentários realizados em oficinas e coletivos de produção de diversas cidades brasileiras, para diante do tema de cada um deles, elaborar a seguinte pergunta: como se apreende uma determinada vivência? Essa interrogação será o guia do texto, cujas respostas sinalizam para um importante eixo que estrutura a produção audiovisual periférica acima apontado: a apreensão do cotidiano.

O debate a seguir apresenta dois eixos: o primeiro se apropria da experiência cotidiana e periférica para se reportar diretamente aos meios de comunicação de massa, problematizando as imagens e imaginários engessados sobre a periferia que costumam circular em diversos produtos midiáticos. O segundo eixo abandona o tom de resposta explícita para se ocupar das variadas manifestações e composições do cotidiano periférico: histórias do lugar, pessoas e sociabilidades. Os temas escolhidos se reportam a experiências vividas por quem mora na periferia, mas não somente. Assim como há uma exploração das temáticas que transcendem o território, consideradas "universais", em que as respostas à mídia hegemônica cedem espaço para o debate de temas que vão além das especificidades dos espaços periféricos.

\section{O DOCUMENTÁRIO COMO RESPOSTA EXPLÍCITA ÀS MENSAGENS DA MÍDIA HEGEMÔNICA}

Para iniciar a discussão, recorro ao documentário Não é o que é (Oficinas Kinoforum, 2004). Esse filme toca numa das questões cardeais da composição estética e, especialmente, 
discursiva dos documentários periféricos: a rejeição às imagens e aos imaginários de inúmeras mensagens midiáticas que tomam periferias e favelas como locais unicamente inseguros e violentos. Rodado no Jardim São Luís, bairro da zona sul de São Paulo, o documentário seleciona uma série de depoimentos de moradores que ressaltam as dinâmicas e sociabilidades do lugar que não geram interesse nos meios de comunicação. Como Não é o que é, há uma série de outros filmes do cinema de periferia que adotam esse encaminhamento discursivo, tornando essa opção um traço presente até hoje em diversos documentários.

Acessar os meios de produção permite expressar em imagens e sons aquilo que incomoda, especialmente as construções imagético-discursivas que estigmatizam os moradores das periferias. Em Imagens de satélite, realizado na Oficina de Imagem Popular, em Brasília, um dos depoentes desabafa: "é muito difícil morar em periferia, a gente é discriminado o tempo todo, entendeu? O cara pensa que você já vai roubar (...) é a discriminação que você sente na pele, se eu tivesse condições eu me mudaria". Depoimentos como esse revelam que morar na periferia é um ônus, uma nódoa, um carimbo que impregna seus moradores e os tornam alvo da experiência diária de serem vistos como cidadãos de segunda categoria. Essa ideia é reforçada por diversos discursos da mídia de massa, como atestam vários documentários desta produção.

Isso não implica negar a existência da violência e da marginalidade em periferias e favelas. No entanto, a reivindicação de documentários como Não é o que é é de se não tomar a parte pelo todo. A música, especialmente por meio do rap, já se consolidou como uma importante ferramenta artística para propor novos modos de enxergar as periferias, assim como as pessoas que lá moram. Nos últimos 15 anos, aproximadamente, literatura ${ }^{1} \mathrm{e}$ audiovisual também exercitam esse objetivo essencialmente político e estético. Logo, o trabalho de responder à pergunta que orienta este capítulo deve atentar às diversas gradações desse "direito de resposta".

Essa questão está diretamente atrelada às políticas de representação que os documentários periféricos acionam. A identificação do movimento descrito acima evidencia uma disputa em torno do que merece visibilidade, em que espaços, pessoas e experiências se tornam a matéria-prima para a confecção da representação. Se as produções televisivas e cinematográficas hegemônicas dependem da prevalência de representações socioculturais que constroem uma realidade social compartilhada, o cinema de periferia necessita, então, de diferentes formas de elaborar a vivência, para que assim ele possa destacar as periferias para

\footnotetext{
${ }^{1}$ Para detalhes sobre a "literatura marginal" produzida nas periferias de São Paulo, ver o trabalho de Nascimento (2009).
} 
além das visões homogêneas e engessadas. Nessa direção, documentários como Não é o que $e ́$, quando contestam os conteúdos enviesados das mensagens da grande mídia, sinalizam para a construção de um modelo representativo que inclui a periferia "no universo do que é visível" (como aponta Hamburger, em outro contexto), "mas não às custas de aparecer como exceção no habitat da barbárie” (HAMBURGER, 2003, p. 56). Isso implica a revisão de práticas e valorações quando se apreende a experiência alheia, pois a divulgação em larga escala de uma imagem redutora não se limita à exibição, mas ajuda a construir imaginários que cristalizam histórias, pessoas e sociabilidades vinculadas às periferias, imaginários que levam tempo para serem desconstruídos. Minimizar os efeitos desse interesse espetacular, no sentido mais problemático do termo, é, portanto, o objetivo de muitos documentários da produção documental periférica.

\section{O COTIDIANO EM SUAS COMPOSIÇÕES MATERIAIS: RESPOSTA IMPLÍCITA OU O DESEJO DE CONTAR UMA HISTÓRIA?}

A elaboração da vivência não passa unicamente pelo explícito tom de resposta às mensagens da mídia. Em diversos documentários, a intenção é frisar a experiência cotidiana balizada na arte e no relacional (questões que não interessam aos programas vespertinos do tipo "mundo-cão"), como um modo de driblar ou minimizar o estigma. Há, nessa direção, uma infinidade de documentários que procuram ressaltar a produção cultural e artística presente nas periferias, morros e favelas. As práticas vinculadas ao movimento hip-hop break, graffiti e rap - são temas recorrentes, mas também há filmes que se voltam para a produção literária, como o Prosa e poesia no morro (Favela é isso, 2008), que ouve compositores e poetas de diversos morros e favelas da periferia de Belo Horizonte, ou o Curta saraus (Arte na Periferia, 2010), que faz um passeio por diversos saraus da periferia de São Paulo para demarcar as aproximações entre arte e política. As manifestações culturais (especialmente as musicais) de cada lugar também são foco de muitos documentários, entre os quais Coco de umbigada (Gambiarra Imagens, 2008), que conta desde o surgimento o ritmo que intitula o documentário à importância social e artística para diversos bairros da periferia de Olinda, ou Mundo do funk (Cinema Nosso, 2005), sobre o funk carioca e assuntos correlatos.

Esses documentários demonstram que há, no conjunto da produção documental periférica, outras gradações dessa empreitada que merecem uma atenção mais efetiva. A partir de agora pretendo me deter na que se apropria das experiências cotidianas relacionadas a 
espaços e pessoas. De modo geral, essa apropriação se reverte nos documentários periféricos em dois significativos eixos: 1) histórias e impressões de um lugar; 2) personagens considerados importantes para uma comunidade. É evidente que no trabalho de elaborar a vivência a partir do cotidiano a produção periférica não se limita a esses dois tópicos. A forma como esses documentários se aproximam de um determinado tema e como isso se materializa na imagem e no som permite, já num primeiro momento, apontar que a incorporação do cotidiano a partir desses dois aspectos revela uma interessante ambiguidade: quando se apropriam de espaços, pessoas e sociabilidades, sem utilizar o tom de reposta direta, esses filmes dão uma resposta indireta aos meios de comunicação de massa ou abstraem essa questão e focam as atenções no desejo de simplesmente contar uma história?

Isso sinaliza para a apropriação do cotidiano como uma estratégia política comum no cinema realizado nas periferias, ou seja, ultrapassar o estigma ao incorporar o que é pouco visível e dessa forma propor um novo olhar para os espaços periféricos? Nessa direção, a perspectiva de Michel de Certeau se torna uma importante referência para o estudo da presença do cotidiano no cinema de periferia. Este autor apresenta um dos mais significativos trabalhos sobre as composições e funcionamentos da esfera cotidiana, cuja estratégia epistemológica serve de inspiração para esta tese. De Certeau se interessa pelo cotidiano a partir daquilo que é tangível: andar pela cidade, ler, cozinhar, rezar, habitar, falar, a reapropriação cultural. São inúmeras atividades que deslocam o cotidiano de um plano geral e abstrato para um cotidiano material. A partir desse reconhecimento, pode-se pensar nas articulações entre cotidiano, política e história, conforme aponta a perspectiva de Martins e Pais, que aqui serão úteis também para o desenvolvimento do debate.

Isso não implica que farei uma adaptação literal do trabalho de Michel de Certeau ao meu, ou seja, não seguirei o mesmo percurso metodológico de modo a também identificar as configurações do andar pela cidade, comer, cozinhar ou ler. Para este autor, inventar o cotidiano vincula-se à produção e ao consumo de uma série de ações ordinárias, que, num primeiro instante, não apresentam uma localização exata, mas são assim definidas ou enquadradas por uma "ordem econômica dominante" (CERTEAU, 2008, p. 39). Isso induz a uma variedade de "maneiras de fazer" das "artes do fraco" (ou dos consumidores, como diz o autor) que ganha corpo numa marginalidade de massa que é heterogênea e não prescinde do "ato de falar" (CERTEAU, 2008, p. 40). Segundo Certeau, falar não se restringe ao domínio 
de uma língua, mas ao modo como a organização da enunciação ${ }^{2}$ se estende às práticas da vida cotidiana, repaginando conjunturas sociopolíticas.

Essa perspectiva torna-se, portanto, uma útil ancoragem que instiga as seguintes questões: como os realizadores periféricos inventam o cotidiano nos documentários que produzem? Uma vez que a fala transcende a enunciação linguística, como tais realizadores "falam" nesses filmes? Se o cotidiano torna-se um elemento constitutivo dos pontos de vista da produção documental periférica, como ele é apropriado, então, por esses documentários? Ao postular a materialidade do cotidiano, é válido destacar que essa característica é também uma questão de recorte, uma opção, uma invenção. Daí a importância de investigar o modo como essa produção documental recorre às inúmeras facetas da vida cotidiana para a construção de uma determinada vivência, pois “o trivial não é mais o outro", defende Certeau (2008, p. 63), “é a experiência produtora do texto". Se o documentário pode ser visto também como um texto, ele se torna, então, um espaço privilegiado para a circulação das experiências cotidianas em suas diversas composições - alteridades, familiaridades, exterioridades.

\subsection{Histórias e sensações do lugar: espaço urbano e clausura}

Para responder às perguntas anteriormente postas, recorro a documentários que tocam no primeiro ponto apresentado: histórias do lugar. São inúmeros os filmes que contam a história de uma determinada localidade geralmente obedecendo a uma estrutura narrativa cujo foco vai das origens aos dias de hoje. Na maioria dos casos, esse lugar escolhido como "personagem" é o bairro onde moram os realizadores. O resgate de Perus (Kinoforum, 2007), Cidade do sol (Refazendo Vínculos, 2006), Maravilha tristeza (Kinoforum, 2002), Capuava unida (Kinoforum, 2005) e Pari (Nossa Tela, 2008) são todos documentários que contam a história de um bairro. O que aproxima todos esses filmes é uma estrutura que alterna depoimentos com imagens da localidade, às vezes de arquivo, com uma proposta visual e narrativa recorrente nos documentários expositivos (NICHOLS, 1991).

Há, no entanto, documentários que também se apropriam de um espaço, mas apostando em outras estratégias narrativas, estéticas e representacionais. Cidade cinza (Rede Jovem Cidadania, AIC, 2008) é um filme que aciona essa possibilidade. Ele não conta a

\footnotetext{
${ }^{2}$ Segundo Michel de Certeau, o ato de falar "opera no campo de um sistema linguístico; coloca em jogo em jogo uma apropriação, ou uma reapropriação, da língua por locutores; instaura um presente relativo a um momento e a um lugar; e estabelece um contrato com o outro (o interlocutor) numa rede de lugares e de relações. Estas quatro características do ato enunciativo poderão encontrar-se em muitas outras práticas (caminhar, cozinhar etc.)" (2008, p. 40, grifos do autor).
} 
história de um bairro, mas trata das experiências, desventuras e contradições da experiência urbana. Cidade cinza tece uma série de considerações sobre o funcionamento de um grande centro urbano, priorizando experiências, impressões e sensações decorrentes da cidade.

Cidade cinza se denomina um documentário poético. Ao tomar a classificação de Nichols para designar esse tipo de documentário, de fato, sua vertente poética se confirma, uma vez que não há entrevistas e narrações explicativas, mas planos longos com comentários em voz over que nem sempre se referem às imagens. Essa estrutura permite ao filme oscilar entre impressões do espaço urbano, mais gerais, e impressões subjetivas, mais pessoais. Alternadamente, ouvimos em over um homem e uma mulher (que percebemos, pelo timbre de voz, ser uma senhora). São essas vozes que tecem a costura narrativa e sensorial do documentário, estabelecendo uma espécie de negociação que equilibra a importância da voz e das imagens em sua fragmentada narrativa. Esse é o ponto central, segundo Bruzzi, para o debate em torno do papel da voz over.

Esse elemento, também em sua modalidade off, tornou-se indissociável do tipo de documentário que a escola inglesa de John Grierson ajudou a consolidar nos anos 30, influenciando as gerações seguintes para além da Inglaterra. Devido ao tom formal e informacional, esse recurso foi usado para informar ou explicar sobre temas que possivelmente estariam de fora da fala dos personagens. Nos anos 60, a voz off e over nos documentários brasileiros era, em muitos casos, utilizada como um juízo de valor definitivo que lhe rendeu a denominação de "voz de Deus" ou "voz do saber" (BERNARDET, 2003). No entanto, estudos recentes reivindicam que a voz over não pode ser vista unicamente como recurso de projeção de poder, mas, para além dessa possibilidade, deve-se investigar a relação que estabelece com as imagens, pois assim emerge uma diversidade de usos e funções.

A própria história do documentário fornece uma infinidade de exemplos em que o uso da voz, seja over ou off, não corrobora a perspectiva da voz de Deus. Estudos apontam para um caráter heterogêneo no modo de utilização da voz que se afasta de uma perspectiva “didática e antidemocrática" (BRUZZI, 2008, p. 48) ou "pedante e redundante" (KAHANA, 2008, p. 93). Cidade cinza confirma essa perspectiva, pois recorre à voz over para se posicionar sobre questões empíricas, como também existenciais: "no meu ponto de vista, a selva de pedra, eu acho ela às vezes cheias de seres assim, sabe. (...) As baleias de aço, que carregam as pessoas pra lá e pra cá, num trânsito caótico. As baleias de ação são os ônibus, assim. Eu acho elas cheias de seres, assim, às vezes". Essa voz, inclusive, estabelece uma relação com as imagens que se distancia do didatismo e da ilustração. Nesse exemplo, enquanto a homem tece as suas impressões sobre a cidade, não há imagens de ônibus ou do 
trânsito caótico, referências contidas em sua fala; mas um plano geral e fixo de vários prédios, que permite ao espectador perceber apenas parte da "selva de pedra". Mais para o final de seu depoimento, enquanto fala do trânsito, vemos um intenso fluxo não de carros, mas de pessoas captadas da cintura para baixo (fotograma 1). Logo a seguir, um plano aberto e geral de trilhos de uma estação de trem sem movimento (fotograma 2).

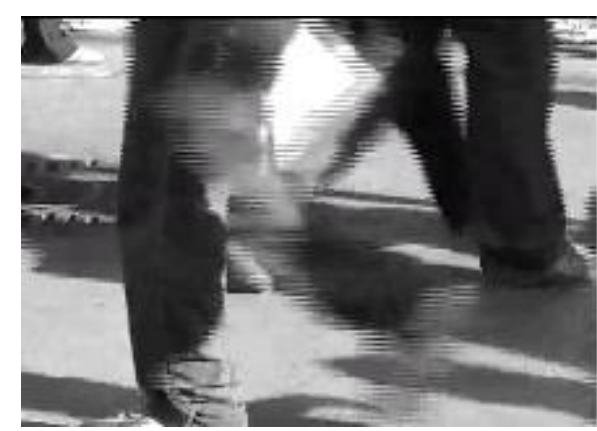

fotograma 1

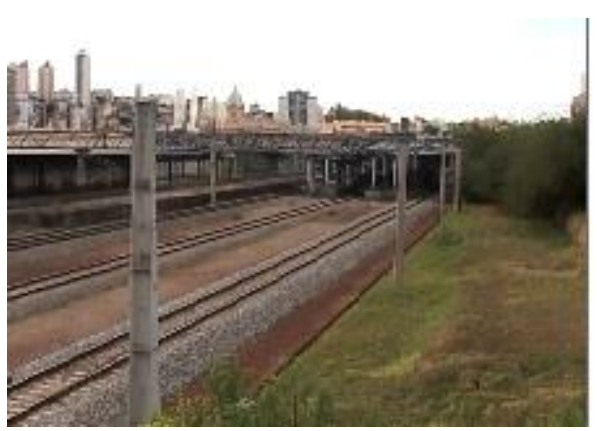

fotograma 2

O documentário transfere para a voz over dos seus personagens aquilo que não encontra mais tempo e espaço no ritmo frenético da selva de pedra. Desse modo, seguindo as trilhas de Kahana, a voz não se limita a uma questão de empoderamento, mas é uma opção estilística que pode ser utilizada de inúmeros modos (KAHANA, 2008, p. 92-93). Diante de um plano geral e aberto captado do alto de um prédio, vemos a cidade, à noite, em pleno funcionamento, com o trânsito intenso, as luzes dos prédios, barulho. Em paralelo, a voz over masculina se indaga: "a cidade me conforta? É o olhar de luta das pessoas, a perseverança que... nem sei se me conforta, não, mas, sei lá, nem sei, cara. É o sorriso da criançada, véi. É o sorriso da criançada que tipo não vê... esses dragões, sabe, é o olhar das crianças, o sorriso das crianças, me confortam”. Nesse segmento, a articulação entre imagem e voz reforça um sentimento de cidade fragmentada e hostil, onde o cotidiano atravessado pelo ritmo alucinante de uma metrópole inibe a expressão mais fluida de sentimentos e subjetividades. Sensação que o documentário tenta reverter por meio desse depoimento em over.

Em outro momento, ouvimos a voz masculina em over: "ofusco a luz dos olhos pardos, nos dias cinza me disparo, me vejo dentro de um mar de concreto, não tão escuro e nem muito claro, mas sempre muito calmo, onde me encontro no áspero toque-vento e asfalto, mas um dia iluminado". Na imagem, uma senhora é captada de costas, de frente para uma grade. Vê-se que o que resta são cacos, vestígios, pistas de uma série de impressões que acompanham também o ritmo das imagens da cidade no desenrolar do documentário. Isso sinaliza que a "cidade filmada" é sempre parcial, onde elementos não visíveis podem, em 
PROGRAMA DE PÓS-GRADUAÇÃO EM COMUNICAÇÃO DA UNIVERSIDADE FEDERAL DE SANTA MARIA

certa medida, ganhar materialidade por meio da voz over que atravessa todo o filme. A relação entre ver e dizer se torna conflituosa e turva. A resolução desse dilema encontrado pelo documentário, como mostra esse segmento, é a correspondência entre imagem e voz distanciada de hierarquias e ilustrações.

Esse aspecto se torna latente em diversas passagens em que os planos são estáticos, longos, sem movimentação de pessoas ou carros, contrapondo à ideia de que um centro urbano é necessariamente o lugar da mobilidade, da pressa, do corre-corre, e não da fixidez, de tempos mortos, contemplativos, até. Em oito de suas quinze sequências, Cidade cinza faz uso dessa opção estilística, em que o céu parece ser uma alternativa a uma cidade repleta de prédios, poeira, poluição, barulho. O elemento humano é pouco diferenciável: sempre em conjunto, coletivamente; pés, corpos da cintura para baixo. Não por acaso, o céu surge como uma possibilidade de fuga, de descanso, do aprazível. Ao priorizar as imagens do céu como contraponto para a "cidade cinza", o documentário traça, paradoxalmente, um movimento que procura abrigo naquilo que integra o espaço urbano apenas como paisagem. $\mathrm{O}$ céu não se configura como elemento material para a cidade (embora em sua essência, ele seja), como os prédios, os trens, as pessoas. Por esse motivo, as tomadas em que ele ocupa quase todo o plano se tornam elucidativas da necessidade de buscar refúgio em outro meio, dessa vez, não urbano (fotograma 3).

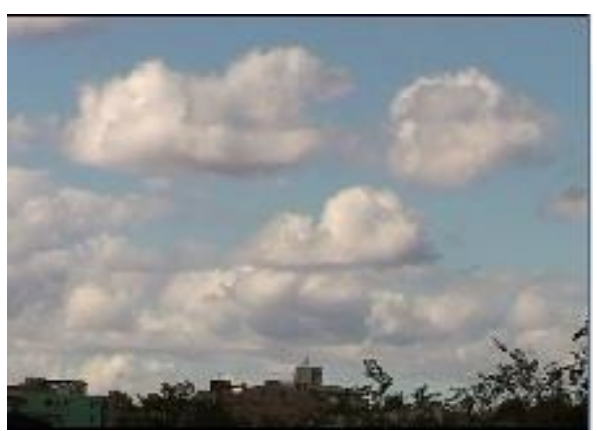

fotograma 3

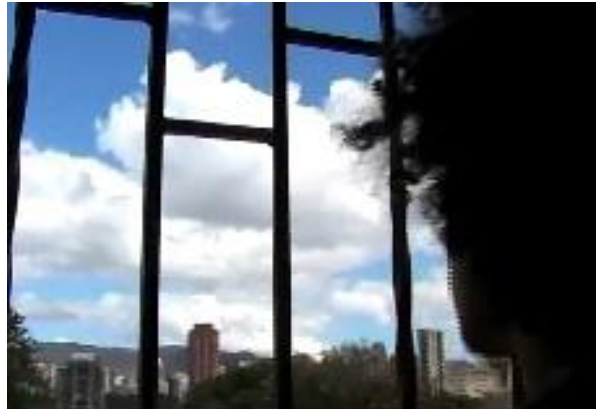

fotograma 4

Em contrapartida, quem recebe mais atenção do ponto de vista da imagem é uma pomba. Em dois segmentos, esse bicho, que vive em bandos nas grandes cidades, aparece sozinho. No primeiro, vemos uma pomba solitária aparece em close, em meio à intensa circulação de pessoas. No segundo, outra pomba também em close e, na medida em que a câmera vai se afastando, vemos que ela está, sozinha, em cima de um vagão de um trem estacionado. A câmera vai se distanciando até a pomba desaparecer no quadro e a imensidão da cidade tornar-se evidente. O elemento humano, sozinho, também aparece no documentário, 
mas sempre captado de costas, de frente para uma grade (fotograma 4). Nos únicos momentos em que os seres vivos são enquadrados mais de perto, há um encontro de sensações: o de prisão ao ar livre proporcionado pela metrópole (evidente nas cenas das pombas) e, inversamente, o sentimento de clausura, quando essa pessoa é enquadrada atrás de uma grade.

O documentário aborda uma micro-história para evidenciar o quanto a composição de uma cidade é multifacetada. Nesse ensejo, o que diz Deleuze sobre o espaço em Bresson é útil para pensarmos a relação que aproxima esses dois filmes: "o que manifestam, a instabilidade, a heterogeneidade, a ausência de ligação de um tal espaço, é uma riqueza em potenciais ou singularidades que equivalem às condições prévias a qualquer atualização, a qualquer determinação" (DELEUZE, 2004, p. 153). Esse documentário revela uma tensão e um descompasso entre a polifonia ${ }^{3}$ e a clausura. Nesse caso, uma sensação de clausura em seu sentido mais metafórico, que remete a um rechaço material e simbólico que os moradores das periferias, favelas e subúrbios experimentaram ao longo da história, mas que, nos últimos anos, com a reconfiguração das práticas culturais e políticas, tem sido minimizado.

Nesse caso, a clausura não é necessariamente espacial, mas relacionada a experiências e sensações. Esse espaço é diverso e heterogêneo e não faria sentido aqui fincar um único posicionamento em relação ao modo como as periferias são tratadas em sua produção audiovisual, mas atentar para a perspectiva de que "as práticas do espaço tecem com efeito as condições determinantes da vida social” (CERTEAU, 2008, p. 175). Mais importante que essa tentativa é perceber que a história do lugar pode ocorrer por meio das impressões e sensações proporcionadas pelo espaço urbano. A análise de documentários que apostam nessa perspectiva se mostra mais enriquecedora do que necessariamente o foco em filmes que contam linear e explicitamente a história de um bairro ou de uma cidade. Logo, a invenção da vivência urbana acena para a possibilidade de extrair a história daquilo que não é imediatamente visível, em que o espaço urbano, o centro, a selva de pedra ou as consequências do "progresso" tornam-se, assim, matéria-prima para essa construção.

\subsection{A escolha do personagem}

Se o cotidiano é constituído por práticas relativas a lugares, sociabilidades e pessoas, não sendo, portanto, uma categoria abstrata, a produção documental periférica ratifica esse

\footnotetext{
${ }^{3}$ Para Canevacci, a cidade polifônica seria "uma cidade narrada com diversas técnicas interpretativas, cada qual diferente uma da outra, mas convergindo todas para a focalização de um paradigma inquieto: a abstração epistemológica da forma-cidade e as emoções do perder-se no urbano" (grifo do autor).
} 
argumento com uma infinidade de documentários que escolhem uma pessoa como tema, apontando para uma segunda gradação da análise da experiência cotidiana.

Basicamente vinculado aos estudos do cinema de ficção, o papel e a importância do personagem (ou do ator social, como preferem alguns estudiosos ${ }^{4}$ ), ainda é pouco estudado no âmbito do cinema documental. Na produção aqui em foco, quando pessoas se tornam "objeto" de um documentário, percebe-se, de modo genérico, três tipos de vínculos que justificam tal escolha: em primeiro lugar, pessoas consideradas importantes para uma comunidade, por sua atuação ou experiência com alguma atividade profissional ou artística. Nesse quesito a faixa etária é bastante variável, podendo ir de jovens a idosos. Uma segunda derivação se refere a personagens históricos que, de modo direto ou indireto, apresentam algum tipo de vínculo com as questões relacionadas às periferias e favelas. E, por último, vínculos afetivos e de amizade que impulsionam a confecção de um determinado documentário.

Saliento desde agora que essa classificação não pretende ser fixa, mas sim localizar traços recorrentes em relação aos documentários que escolhem uma pessoa como personagem central. Adianto também que, em virtude do número significativo de documentários que sinalizaram para essa classificação e também atento aos limites deste texto, centro as atenções em um documentário. A intenção é perceber em que medida o personagem desse filme permite a análise da apropriação e das representações cotidianas.

Começo, então, pela aspecto relacionado aos vínculos afetivos. Um documentário que permite dimensionar essa questão é Maria Capacete (Oficinas Querô, 2006). Maria Capacete é o apelido de Maria Félix dos Santos, uma senhora de aproximadamente 50 anos, que apresenta algum tipo de distúrbio mental, do qual o filme não fornece muitos detalhes. Moradora da favela México 70, na cidade de Santos, litoral paulista, Maria é bastante conhecida na comunidade onde mora, de modo que "quem não conhece Maria é porque ainda não nasceu", como destaca uma das depoentes. Maria não gosta desse apelido, que decorre de um corte de cabelo que usou no passado. Além da personagem central, o documentário ouve nove pessoas, todas moradoras da comunidade e que a conhecem há bastante tempo.

Sua estrutura narrativa é composta por dez temas que vão se encadeando por meio das falas dos entrevistados e de Maria. Cada tópico apresenta a seguinte sequência: os depoentes falam sobre Maria e na sequência ela aparece reforçando o que foi dito ou acrescentando

\footnotetext{
${ }^{4}$ Para Nichols (1991, p. 42) o termo "ator social" permite "dar ênfase a um grau em que os indivíduos se apresentam por si mesmos para os outros. Isso conduz a uma interpretação. Este termo também nos lembra que os atores sociais, as pessoas conservam a capacidade de atuar dentro do contexto histórico em que atuam. (...) A interpretação dos atores socais, não obstante, é semelhante a dos personagens de ficção em muitos aspectos. Os indivíduos apresentam uma psicologia mais ou menos complexa e dirigimos nossa atenção para seu desenvolvimento ou destino".
} 
alguma nova informação. ${ }^{5}$ A partir dos tópicos que seleciona, a montagem nos apresenta sua história de vida e sua relação com a comunidade onde vive.

Esse modo de aproximação com os temas correlatos à personagem funciona como uma espécie de "introdução" sobre Maria. A primeira imagem do documentário é de sua protagonista. Mas, em relação à fala, vizinhos e amigos é que a apresentam, que comentam sobre momentos difíceis de sua vida, quando, por exemplo, perdeu um filho com seis meses de nascido e posteriormente a guarda de um outro filho de criação. Motivo, segundo os entrevistados, que a fizeram "ficar meio perturbada da cabeça". Maria parece arisca, desbocada, sem preocupações com o que fala e como fala. Diante disso, a montagem do documentário sugere que, por ser uma pessoa "diferente", ela precisa ser sempre apresentada por alguém, para que assim o espectador possa se preparar para o que virá.

Num misto de compaixão e pena pela personagem, muitos entrevistados fazem questão de frisar o quanto gostam dela e o quanto ela é querida no bairro. Mas é nesse momento que Maria deixa de lado o tom de reforço ou complemento de informações para se posicionar. Isso ocorre quando os vizinhos e conhecidos relatam alguns serviços que Maria se propõe a fazer, entre eles ficar a noite toda na fila do posto de saúde para guardar o lugar de alguém, que, por esse serviço, lhe paga $\mathrm{R} \$ 10,00$. Alguns depoimentos demonstram indignação com "essa falta de respeito" e a própria, apesar da aparente perturbação mental, é bastante lúcida ao declarar que "aqui só tem amigo no interesse". Nessa direção, as considerações de Migliorin sobre Estamira (Marcos Prado, 2005) contribuem para o entendimento do jogo dual referente à personagem, presente também em Maria Capacete: "os processos que encaixam cada sequência do filme dentro da lógica dicotômica loucura/lucidez ou fúria/afeto são justamente as estratégias que impossibilitam a inadequação da personagem em relação ao filme e ao espectador" (MIGLIORIN, 2008, p. 255).

Embora as experiências traumatizantes porque passou apontem para essa condição, o documentário não coloca Maria na posição de vítima, nem por parte dos "experts"6 e nem pela própria Maria. Essa característica é apreendida a partir do momento em que a personagem é vista como uma pessoa que, apesar da perturbação mental, tem uma boa relação com os vizinhos e amigos; gosta de ir ao forró, mas não de dançar; prefere vinho à cachaça e

\footnotetext{
${ }^{5}$ Há, no entanto, apenas um momento em que o tom de complementaridade dá lugar à contradição: quando Bolinha, dono de um bar na comunidade, diz que costuma dar a Maria uma dose de pinga, quando está frio, e que ela não é de dar vexame quando bebe. Maria, por sua vez, contradiz a fala do entrevistado, ao afirmar que Bolinha nunca lhe deu nada, além de fazer a seguinte pergunta: “quieta, eu? quando bebo?".

${ }^{6}$ Recorro à expressão de Migliorin (2008, p. 242), em sua análise de Estamira: "Estamira, que até agora estava à frente do filme, agora é narrada, de fora, como se já não pudesse mais se relacionar com aqueles eventos. A filha assume assim a função de expert”.
} 
tem problemas familiares, como qualquer outra pessoa. A "inadequação" a que se refere a citação acima permite ao documentário impulsionar um movimento que vai do estranhamento à aproximação. ${ }^{7}$

As diversas nuanças da personagem emprestam a Maria Capacete um tom de documentário biográfico, ainda que não seja cronologicamente encadeado, mas também um espaço onde se registram relações em que imperam diversos sentimentos e intenções da vida cotidiana. Para isso, o filme equilibra a performance de Maria e sua representação, confirmando a prerrogativa de Vallejo para a importância de se estabelecer uma relação (harmônica) com as diversas modalidades representacionais: "se o cinema renuncia à representação do outro - restringindo seus discursos ao cinema performativo e reflexivo -, o perigo reside num onanismo audiovisual do próprio dispositivo fílmico e seus realizadores" (VALLEJO, 2008, p. 83).

Isso indica que saber sobre Maria é também saber, ainda que de modo parcial e fragmentado, das relações afetivas, de exploração, de aproximação, de admiração, de respeito e da falta dele diante de uma pessoa que exatamente por sua existência "peculiar" serviu de mote para a confecção desse documentário. Há, ainda, principalmente, a possibilidade de se apreender a elaboração de uma vivência que pensa sobre si e sobre os outros, tornando essa personagem, conforme apontado pelas imagens e depoimentos, integrante das relações cotidianas de um bairro de periferia da cidade de Santos. Afinal, a análise da constituição dos personagens se estende à investigação de processos de identificação e das formas de representação social.

\section{CONCLUSÃO}

A produção de documentários periféricos revela uma heterogeneidade de apropriações e elaborações da vivência, uma diversidade que se materializa no modo como se organiza em tais filmes a relação entre imagem, som e discurso. De um filme que aborda explicitamente o tema da periferia a outro que aposta em questões sem vínculo espacial, esta produção evidencia, principalmente por meio dessa última chave, uma recusa aos enquadramentos da representação. Não se trata de privilegiar os filmes que apostam nessa última perspectiva em

\footnotetext{
${ }^{7}$ Conforme aponta Baltar (2008, p. 215-216), em sua análise de Estamira (Marcos Prado, 2005), documentário cuja personagem central também apresenta distúrbios mentais: "A maneira como a câmera invade a geografia da vida de Estamira, formulando quadros que quase penetram na pele de tão próximos, reitera, a um só tempo, a sensação de proximidade e a presença do diretor e do aparato fílmico como instâncias mediadoras do olhar público sobre a personagem".
} 
detrimento de outras, mas de reconhecer a possibilidade de amplitude para a realização audiovisual e para o debate em torno dele.

Sendo assim, deve-se destacar o cotidiano como o local da produção e circulação de conhecimentos e significados comuns que, pautado em "situações de interação" (PAIS, 2003, p. 15), permite o "surgimento de contradições" (MARTINS, 2008, p. 56), exigindo dos indivíduos saber lidar com tensões e instabilidades em constantes processos de negociação e mediação. Este conhecimento comum é a fonte primária para as experiências que possibilitam os modos de ser, estar e fazer na vida cotidiana, e por ser sempre um processo em que o vivido, como um momento de compartilhamento de sentidos e informações, torna-se imprescindível para a compreensão do cotidiano. Com base nesta orientação, os documentários analisados neste texto imprimem uma nitidez a essa possibilidade, pois, como salienta Pais, não se pode tomar o cotidiano como uma categoria distanciada das experiências sociais, pois o desafio que se coloca ao pesquisador diante deste tema "é o de conseguir abrir brechas num debate social polimorfo" (PAIS, 2003, p. 75). Um dos pilares que sustentam os estudos com foco no cotidiano é exatamente a dificuldade em apreender "o imprevisível, o aleatório, o imprevisto" (PAIS, 2003, p. 81) presente nas experiências cotidianas.

Aderindo a essa proposta, pode-se concluir que se o cotidiano é fonte de interação, contradição, produção e troca de conhecimento, é válido destacar mais uma vez as materialidades de sua composição. Os documentários analisados sublinham esse aspecto quando as necessidades diárias forçam o surgimento de redes sociais; ou quando discursos homogeneizantes tentam ser desfeitos a partir do relato da experiência diária por parte de quem mora nestas localidades, como se vê em Não é o que é. Desse modo, é no cotidiano que o ser humano descobre a eficácia das ações políticas. A incorporação do cotidiano no cinema de periferia se torna, portanto, uma estratégia reveladora de clivagens e assimetrias, capaz de apresentar condições de formação e transformação da política e da história.

\section{REFERÊNCIA}

BALTAR, Mariana. Estranhamento e aproximação em Estamira - da eloquência da loucura ao trauma social. In: HAMBURGER, Esther; AMANCIO, Tunico \& SOUZA, Gustavo (orgs.). IX Estudos de Cinema Socine. São Paulo: Annablume, 2008.

BERNARDET, Jean-Claude. Cineastas e imagens do povo. São Paulo: Companhia das Letras, 2003.

BRUZZI, Stella. New documentary. 2. ed. Londres: Routledge, 2006. 
CANEVACCI, Massimo. A cidade polifônica. Ensaio sobre a antropologia da comunicação urbana. 2. ed. São Paulo: Studio Nobel, 2004.

CERTEAU, Michel de. A invenção do cotidiano: 1. Artes de fazer. 14. ed. Petrópolis: Vozes, 2008.

DELEUZE, Gilles. A imagem-movimento. Cinema 1. Lisboa: Assírio \& Alvim, 2004.

HAMBURGER, Esther. Política de representação. Contracampo. Niterói, vol. 8, $1^{\circ}$ semestre de 2003, p. 49-60.

KAHANA, Jonathan. Intelligence work: the politics of american documentary. Nova York: Columbia University Press, 2008.

MARTINS, José de Souza. A sociabilidade do homem simples. São Paulo: Contexto 2008.

MIGLIORIN, Cezar. Eu sou aquele que está de saída: dispositivo, experiência e biopolítica no documentário contemporâneo. Rio de Janeiro: Escola de Comunicação/UFRJ, 2008. Tese de doutorado.

NASCIMENTO, Érica Peçanha do. Vozes marginais na literatura. Rio de Janeiro: Aeroplano, 2009.

NICHOLS, Bill. Representing reality: issues and concepts in documentary. Bloomington: Indiana University Press, 1991.

PAIS, José Machado. Vida cotidiana: enigmas e revelações. São Paulo: Cortez, 2003.

VALLEJO, Aida. Protagonistas de lo real. La construcción de personajes en el cine documental. Secuencias. Madri, no 27, 2008, p. 72-89.

Original recebido em: 12/07/2013

Aceito para publicação em: 14/05/2016

Gustavo Souza

Professor na Universidade Paulista (Unip) gustavo03@uol.com.br

Esta obra está licenciada sob uma Licença Creative Commons. 